\title{
Heparin allergy: Successful desensitization for cardiopulmonary bypass
}

\author{
Kalpaj Parekh, MD, ${ }^{a}$ Harold M. Burkhart, MD, ${ }^{a}$ Ammar Hatab, MD, ${ }^{b}$ Alan Ross, ${ }^{2}{ }^{c}$ and Barbara A. Muller, MD, \\ lowa City, lowa
}

Ч eparin remains the drug of choice required for anticoagulation during cardiopulmonary bypass. Advantages of heparin over other drugs are its rapid onset of action after intravenous administration and its rapid reversibility with protamine. Heparin-induced anaphylaxis, although rare, has been reported. ${ }^{1}$ We report successful desensitization to heparin in a patient requiring pulmonary valve replacement.

\section{Clinical Summary}

A 55-year-old woman with a history of a tetralogy of Fallot repair done at age 10 years presented with congestive heart failure. Transesophageal echocardiography and cardiac catheterization revealed free pulmonary valve insufficiency requiring replacement. The medical history was significant for heparin allergy first observed at the time of the original cardiac surgery in 1959. She had generalized hives and itching immediately after surgical intervention that was thought to be attributable to heparin infusion. In 1970, she experienced pulmonary embolism and was re-exposed to intravenous heparin, triggering immediate onset of generalized hives, itching, and chest tightness. Over the years, routine intravenous line flushes triggered localized self-limited urticaria and pruritus extending up the arm. Our preoperative evaluation uncovered a convincing history for heparin allergy that was thought to be anaphylactoid in nature on the basis of existing literature and the lack of a defined, pathophysiologic, immunoglobulin E (IgE)-mediated mechanism. In the absence of a standardized skin test for heparin hypersensitivity, the options available were to either desensitize to heparin or use an alternate anticoagulant. In view of the anticipated reoperative operation, it was decided to perform cautious intravenous desensitization as the optimal strategy to decrease the potential risk for significant side effects.

Al-Eryani and colleagues ${ }^{2}$ reported heparin desensitization before cardiopulmonary bypass by gradually increasing the dose of heparin intravenously, starting with $100 \mathrm{U}$ in $1 \mathrm{~L}$ of saline over 24 hours. We adapted their dosing protocol by premedicating with acetaminophen (INN: paracetamol) and diphenhydramine (Benadryl, Pfizer) and keeping intramuscular

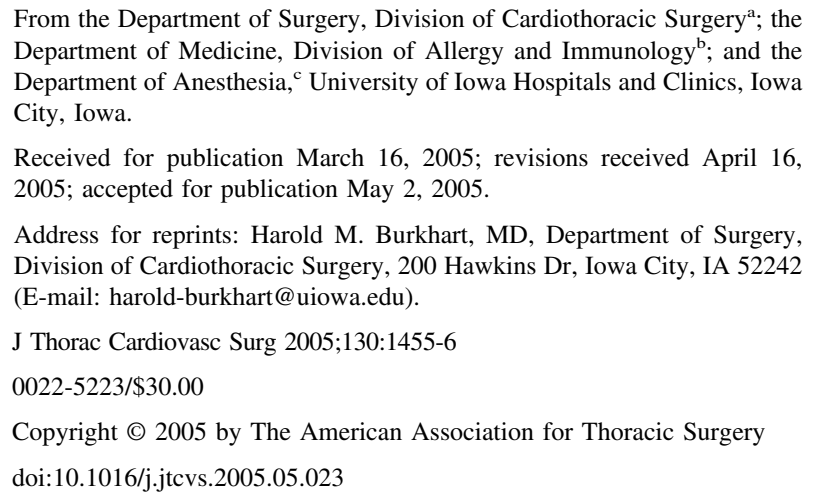

\section{TABLE 1. Protocol for heparin desensitization}

\begin{tabular}{|c|c|}
\hline Day 1 & $\begin{array}{l}10 \mathrm{U} \text { of heparin in } 1000 \mathrm{~mL} \text { of saline at } 42 \mathrm{~mL} / \mathrm{h} \\
\text { for } 24 \mathrm{~h}\end{array}$ \\
\hline Day 2 & $\begin{array}{l}100 \mathrm{U} \text { of heparin in } 1000 \mathrm{~mL} \text { of saline at } 42 \mathrm{~mL} / \mathrm{h} \\
\text { for } 24 \mathrm{~h}\end{array}$ \\
\hline Day 3 & $\begin{array}{l}1000 \mathrm{U} \text { of heparin in } 1000 \mathrm{~mL} \text { of saline at } 42 \mathrm{~mL} / \mathrm{h} \\
\text { for } 24 \mathrm{~h}\end{array}$ \\
\hline Day 4 & $\begin{array}{l}5000 \mathrm{U} \text { of heparin in } 1000 \mathrm{~mL} \text { of saline at } 42 \mathrm{~mL} / \mathrm{h} \\
\text { for } 24 \mathrm{~h}\end{array}$ \\
\hline Day 5 & $500 \mathrm{U}$ of heparin per $\mathrm{h}$ for $24 \mathrm{~h}$ \\
\hline Day 6 & $\begin{array}{l}100 \mathrm{U} / \mathrm{h} 3 \text { hours before initiating cardiopulmonary } \\
\text { bypass }\end{array}$ \\
\hline
\end{tabular}

Adapted with permission from al-Eryani and colleagues. ${ }^{2}$

(0.3 mL, 1:1000 concentration) epinephrine available at the bedside. When the infusion containing $100 \mathrm{U}$ of heparin in 1000 $\mathrm{mL}$ of saline was started, she experienced generalized itching, shortness of breath, diarrhea, and chest tightness within 10 minutes. The infusion was stopped, and intramuscular epinephrine and an oral $\mathrm{H}_{1}$ antagonist were administered, which alleviated the symptoms. On the following day, $10 \mathrm{U}$ of heparin in $1000 \mathrm{~mL}$ of saline was infused over 24 hours. The patient tolerated the heparin concentration well, without allergic side effects. The heparin concentration was subsequently increased to $100 \mathrm{U}$ of heparin in $1000 \mathrm{~mL}$ of saline and infused over the next 24 hours, which was well tolerated. On day 3, the 24-hour infusion consisted of $1000 \mathrm{U}$ of heparin, and on day 4, $5000 \mathrm{U}$ of heparin was infused. By the fifth day, the patient was tolerating $500 \mathrm{U} / \mathrm{h}$ of heparin. On the sixth day, the heparin infusion was temporarily reduced to $100 \mathrm{U} / \mathrm{h}$ to accommodate intraoperative monitoring catheters. Full heparinization was initiated with cardiopulmonary bypass, and pulmonary valve replacement was performed successfully with a No. 29 Mosaic valve (Medtronic, Inc, Minneapolis, Minn). The postoperative course was uneventful, and she was discharged on postoperative day 5. Table 1 depicts the heparin desensitization protocol used preoperatively.

\section{Discussion}

Heparin-induced IgE-mediated hypersensitivity and anaphylactoid reactions, although rare, can pose a serious clinical problem for patients requiring cardiopulmonary bypass. ${ }^{3}$ Standardized skin tests with heparin components are not available to investigate for IgE-mediated heparin allergy, nor are they as reliable as standard penicillin skin tests with major and minor determinant components of the penicillin molecule. Typically, the most commonly encountered adverse reactions to heparin are hemorrhage, delayed hypersensitivity reactions, and heparin-induced thrombocytopenia (HIT). HIT is an autoimmune- 
mediated reaction whereby $\operatorname{IgG}$ and $\operatorname{IgM}$ antibodies are directed against heparin and platelet factor. ${ }^{4}$ Desensitization is not a therapeutic option for acute or delayed HIT. Cases have been reported in which alternative drugs, such as bovine heparin, ancrod, and argatroban, have been used in place of heparin when anaphylactoid reactions are suspected; however, their efficacy has been anecdotal and needs further investigation. ${ }^{4}$

Two reports exist in the literature in which desensitization for heparin allergy was attempted before cardiopulmonary bypass. ${ }^{2,5}$ Until more experience is gained with the use of alternative anticoagulation agents for cardiopulmonary bypass, we advocate the use of heparin desensitization as successfully performed in this case.

\section{References}

1. Bernstein IL. Anaphylaxis to heparin sodium; report of a case, with immunologic studies. JAMA. 1956;161:1379-81.

2. al-Eryani AY, al-Momen AK, Fayed DF, Allam AK. Successful heparin desensitization after heparin-induced anaphylactic shock. Thromb Res. 1995;79:523-6.

3. Bottio T, Pittarello G, Bonato R, Fagiolo U, Gerosa G. Life-threatening anaphylactic shock caused by porcine heparin intravenous infusion during mitral valve repair. J Thorac Cardiovasc Surg. 2003;126:1194-5.

4. Smith RE, Townsend GE, Berry BR, Bowen T. Enoxaparin for unstable angina and ancrod for cardiac surgery following heparin allergy. Ann Pharmacother. 1996;30:476-80.

5. Patriarca G, Rossi M, Schiavino D, et al. Rush desensitization in heparin hypersensitivity: a case report. Allergy. 1994;49:292-4.

\title{
Surgical treatment of recurrent transient ischemic attacks and hemoptysis in a young man with multiple pulmonary arteriovenous malformations
}

\author{
Cliff K. Choong, FRACS, ${ }^{a}$ Daniel M. Goodenberger, MD, ${ }^{\mathrm{b}, \mathrm{c}}$ Daniel Picus, MD, ${ }^{\mathrm{b}, \mathrm{d}}$ and \\ Bryan F. Meyers, MD, ${ }^{\text {a }}$ St Louis, Mo
}

$\mathrm{P}$ ulmonary arteriovenous malformation (PAVM) is a rare vascular anomaly with an incidence of 2 to 3 per 100,000 population. ${ }^{1}$ We present a patient whose therapy with embolotherapy for PAVMs resulted in recurrent transient ischemic attacks (TIAs) and massive hemoptysis requiring treatment by surgical resection.

\section{Clinical Summary}

A 17-year-old man with hereditary hemorrhagic telangiectasia (HHT) had PAVMs incidentally discovered on a chest $\mathrm{x}$-ray film. Investigations confirmed PAVMs without the presence of associated bronchial collateral artery. Although his pulse oxygen saturation at rest was $80 \%$, he was asymptomatic. He underwent embolization therapy with aneurysmal coil placement and cyanoacrylate glue elsewhere (Figures 1A and 1B). One week later, he had the first of recurrent TIAs with tingling and numbness in the

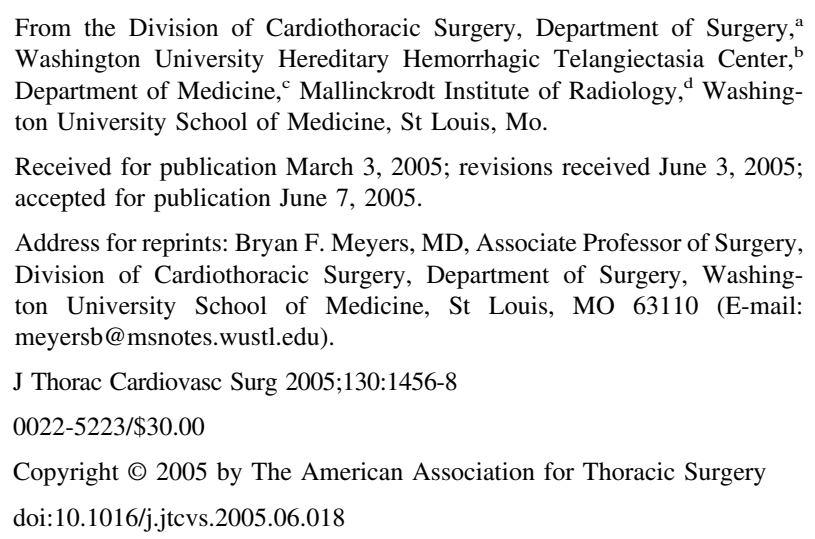

right upper extremity. Investigations including carotid duplex scan, echocardiography, and cerebral CT and MRI did

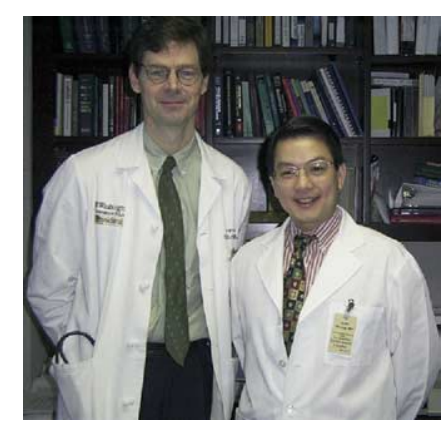

Drs Meyers and Choong not reveal any abnormalities. The TIAs were considered to be most likely caused by emboli originating from clot propagation distal to the coils. Six months later, he had the first of multiple episodes of hemoptysis of 16 ounces or more, which were unresponsive to embolotherapy of several smaller PAVMs. Angiography at our center showed occlusion of the majority of the PAVMs. A large bronchial artery was however seen, supplying an area of neovascularization of the inflammatory complex of cyanoacrylate in the apical segment of the right lower lobe, with rapid filling of the pulmonary vein, implying arteriovenous shunting (Figure 2A). The vessel was larger than the largest Ivalon particles, and an attempt to occlude it by embolotherapy was considered to be potentially hazardous and unlikely to result in a lasting occlusive effect. A decision was made to remove the large PAVMs of the right lower lobe by surgical resection. He underwent an uneventful right lower lobectomy and at 1-year follow-up, he remained well with no further TIA or hemoptysis. A transverse section of the resected lung with coils in the PAVM is shown in Figure 2B.

\section{Discussion}

PAVM was first reported in 1897 by Churton in a 12-year-old boy who had episodes of epistaxis, hemoptysis, and loud pulmonary systolic bruit. ${ }^{2}$ At postmortem examination, he was found to have multiple bilateral PAVMs. More than $80 \%$ of PAVMs are congenital in origin, and of these $60 \%$ to $90 \%$ are associated with HHT. ${ }^{1}$ Conversely, $15 \%$ to $35 \%$ of the population with HHT have a PAVM. The rate of PAVM in our 292 HHT patients was $58 \%$. 